\title{
THE HOUSE THAT JACK BUILT
}

KEITH BARR, 40 Richardson Crescent, Regina, Saskatchewan. S4S 4J3

A few years back I built a birdhouse. I made a one-inch hole for the entrance, just the right size for a wren. I mounted it on the roof of my garage. I expected to have a wren come and nest within a few days. I waited all that summer for a wren to check it out. Nothing came, not even a house sparrow, to see if it would make a suitable home. I left it out all winter to weather.

The house is mounted so that I can see the entrance when I sit at the kitchen table. In the spring I watched the entrance as I ate my meals. Don't ask me what I had to eat - I was so intent on watching that birdhouse that most likely my wife could have put almost anything on my plate and I would have eaten it.

The saying goes that a watched pot does not boil. It could also be said that no bird comes to a watched birdhouse. The House Sparrows are nesting in every nook and cranny they can find, but not one even tries to enter the house that Jack built (okay, so I changed my name for this story).

I have another birdhouse hanging in my apple tree which is about 20 feet from the vacant birdhouse. A wren has built a nest in this house for the last two years, but not once did I ever see the wren go near the birdhouse on the garage. Maybe the house needs more weathering. I leave the house out again all winter long.
Spring comes again. My wife and I are on the deck having one of many coffee breaks that retired people seem to have. We watch a pair of Tree Swallows flying overhead. Low and behold, one swallow actually tries to enter the hole, but alas, I have made the hole too small. The swallows leave. I feel rather dejected. I have come within one half inch of having Tree Swallows in the birdhouse. If the entrance had been cut one and one half inches instead of one inch, the swallow could have gotten in. If I make the hole bigger, maybe next year the swallows will

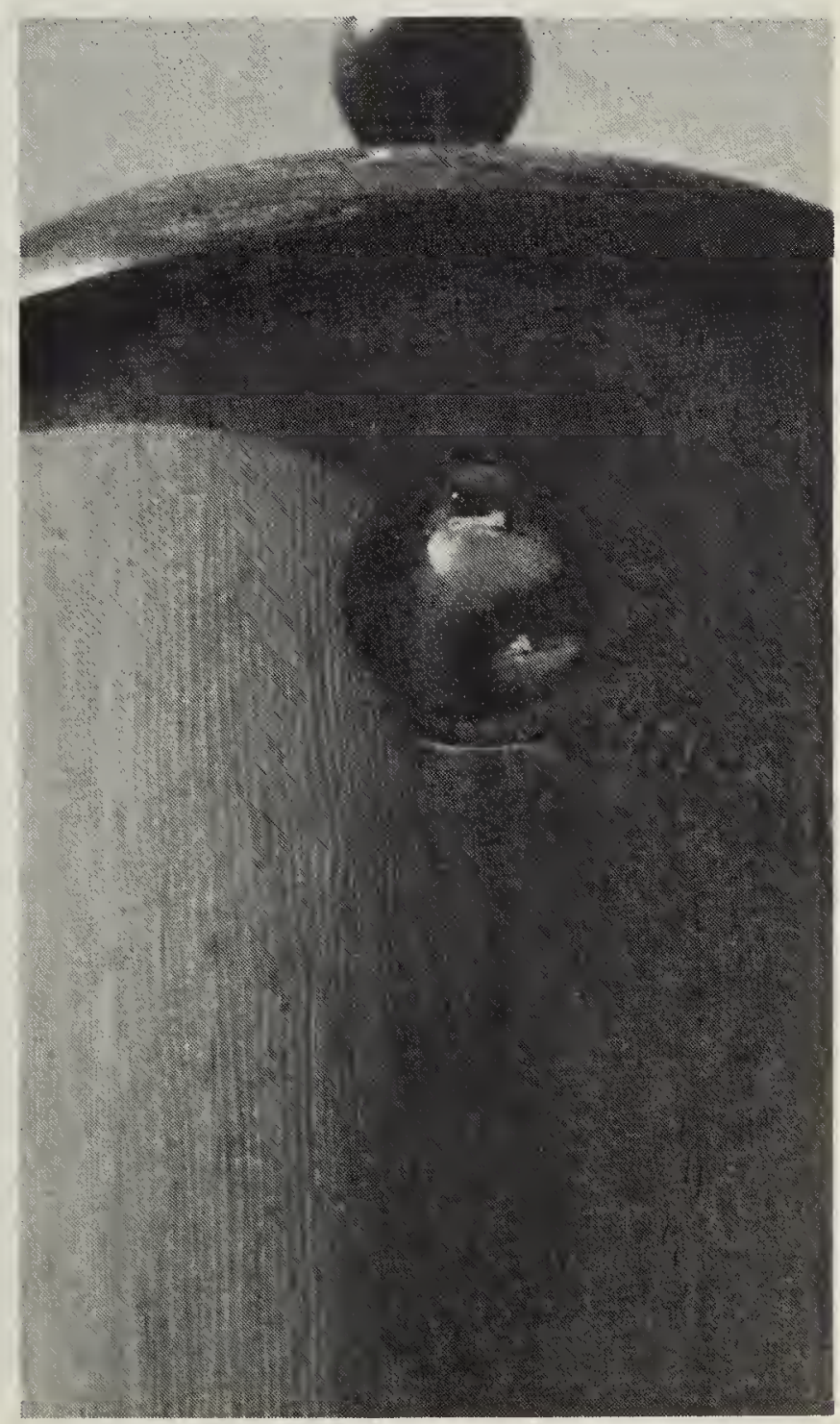

Keith Barr 
nest in the house. Better do it now or I will forget. And I do. That is, I make the hole larger.

The next morning, during coffee, we notice the Tree Swallows circling the house. One swallow perches, looks inside and eventually enters the hole. We watch to see it come out. We wait and wait. No swallow. We are sure that one of us would have seen it come out. I get the ladder and open the house. The swallow is sitting on the floor of the house. Nothing is wrong with the bird as it flies away. I check the bird- house and see the reason the swallow couldn't get out. The distance from the entrance to the floor is too high for the bird to jump. There is not enough room for it to fly and the inside walls are too smooth to climb out. I tack wire screening to the inside wall and replace the birdhouse. No self-respecting swallow is going to return to a place where you can't get out. Oh well, maybe next year.

Next year arrives a few days later when a pair of Tree Swallows take up residency in the birdhouse and raise a family. Success at last!

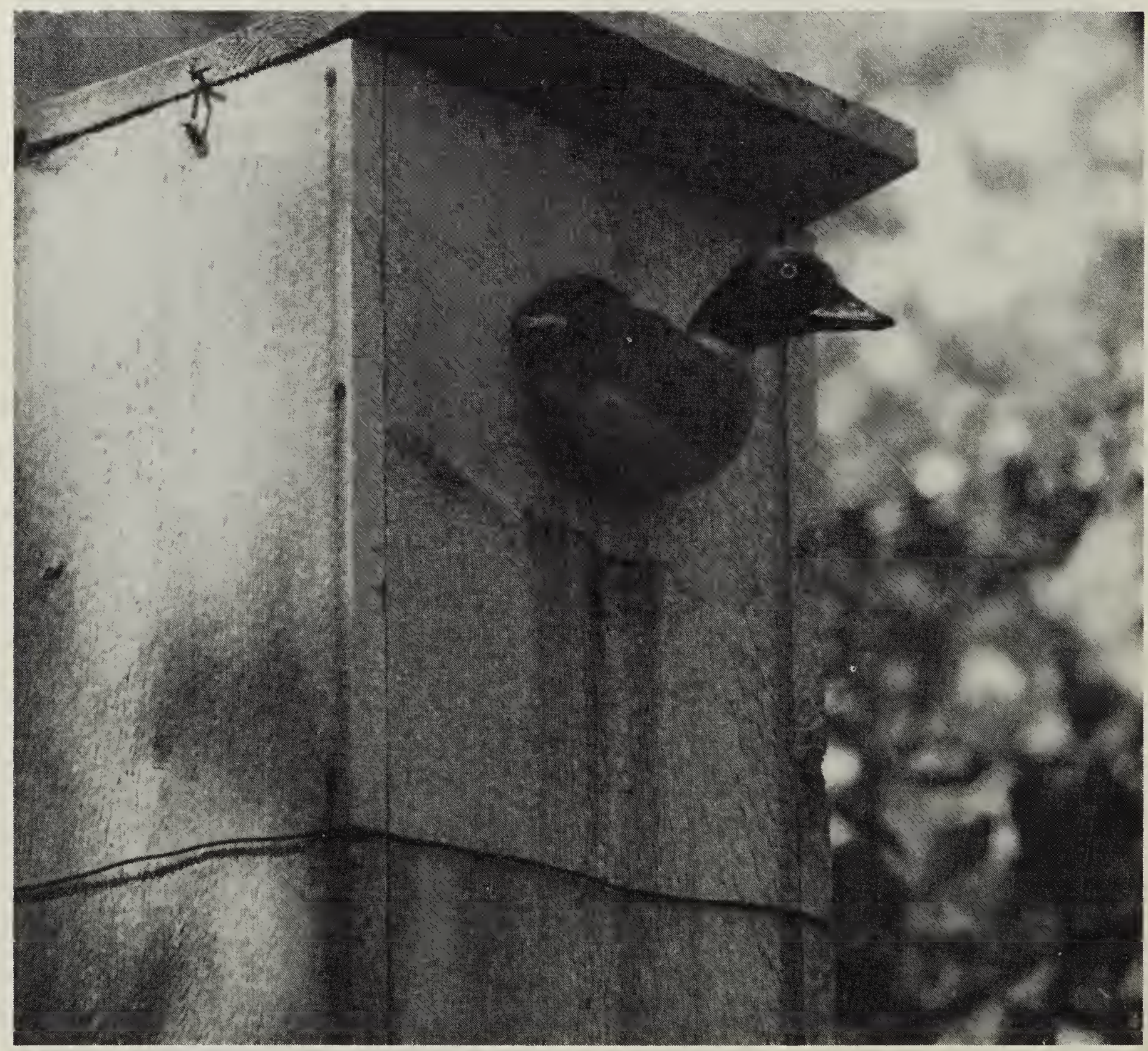

Common Goldeneye sitting in the entrance of her nesting box, 